\title{
Clinicopathological SigNificANCE OF DNA FRAGMENTATION FACTOR 45 AND THYROID TRANSCRIPTION FACTOR 1 EXPRESSION IN BENIGN AND MALIGNANT LESIONS OF THE GALLBLADDER
}

\author{
Yuan Yuan ${ }^{1,2}$, Zhu-Lin Yang ${ }^{2}$, Qiong Zou ${ }^{1,2}$, Li-Fen CAO 2 , Xing-Guo Tan ${ }^{2}$, Song Jiang ${ }^{2}$, \\ XIONG-YING MIAO
}

1Pathology Department, the Third Xiangya Hospital of Central South University, Changsha, China ${ }^{2}$ Research Laboratory of Hepatobiliary Diseases, the Second Xiangya Hospital of Central South University, Changsha, China

\begin{abstract}
Gallbladder cancer (GBC) is one of the most aggressive tumors; we examined the expression level of DNA fragmentation factor 45 (DFF45) and thyroid transcription factor 1 (TTF-1) in benign and malignant lesions of the gallbladder by immunohistochemistry. The results were correlated with clinicopathological features and prognosis. DNA fragmentation factor 45 and TTF-1 expression was significantly higher in gallbladder adenocarcinomas than in the corresponding peritumoral tissues $\left(\chi^{2}\right.$ DFF45 $=6.92, \chi^{2}$ TTF- $1=8.68$, ps $\left.<0.01\right)$, polyps $\left(\chi^{2}\right.$ DFF45 $=4.49, \chi^{2}$ TTF- $1=5.35$, ps $<0.05)$, and chronic cholecystitis $\left(\chi^{2}\right.$ DFF45 $=12.98, \chi^{2}$ TTF-1 $=17.74$, ps $\left.<0.01\right)$. Negative expression of DFF45 and TTF-1 was significantly associated with tumor differentiation, tumor mass, lymph node metastasis and invasion of adenocarcinomas ( $\mathrm{p}<0.05$ ). Univariate Kaplan-Meier analysis showed that elevated expression levels of DFF45 and TTF-1 ( $\mathrm{p}<0.05$ ) were closely associated with increased overall survival. In addition, the average survival time of patients with DFF45(+) TTF-1(+) tumors was significantly higher than those with DFF45(-) TTF-1(-) tumors $(p<0.05)$. Finally, multivariate Cox regression analysis showed that negative expression of DFF 45 and TTF-1 was an independent prognostic predictor in gallbladder adenocarcinoma ( $\mathrm{p}<0.05$ ). The expression of DFF 45 and/or TTF- 1 is closely related to the carcinogenesis, progression, clinical behavior and prognosis of gallbladder adenocarcinomas. DNA fragmentation factor 45 and TTF-1 could be progression-associated genes correlating with good prognosis in GBC.
\end{abstract}

Key words: gallbladder neoplasms, gallbladder polyp, chronic cholecystitis, DNA fragmentation factor 45, thyroid transcription factor 1 .

\section{Introduction}

Gallbladder cancer (GBC) is the fifth most common gastrointestinal cancer and the most common biliary tract malignancy in the USA [1-3]. The incidence of gallbladder cancer has undergone a marked increase in China [4]. The surgical removal of the gallbladder with part of the liver and lymph node dissection is currently the most common treatment for resectable GBC. However, GBC is detected at an early stage in only about $10 \%$ of patients, who are viable candidates for surgery. Most cases of GBC are discovered at an advanced, inoperable stage with serosal invasion and metastasis to other organs [5]. Generally, palliative chemotherapy 
and radiation therapy offer almost no benefit in GBC. Patients with unresectable or metastatic GBC have an extremely poor prognosis and most of them die in less than one year following the diagnosis [1]. Thus, precise identification of the lithogenic and other genes that might have a role in GBC susceptibility should help identify individuals at increased risk among susceptible subpopulations [6]. Additionally, identifying functionally important and clinically relevant metastasis genes will provide possible targets for antimetastatic therapy and potentially improve GBC patient prognosis.

DNA fragmentation factor-45 (DFF45) is the substrate of caspase-3, a key point effector molecule in apoptosis, and thus has an important role in apoptotic DNA fragmentation, which contributes to malignant transformation and metastasis $[7,8]$. Recent clinical studies have convincingly linked DFF45 with tumor progression and poor clinical outcomes in many cancer types, including neuroblastoma, esophageal carcinoma, ovarian endometriomas [9-11], and endometrial and ovarian carcinoma $[10,12-15]$. However, the involvement of DFF45 in human GBC has not been reported.

Thyroid transcription factor 1 (TTF-1) is a tissuespecific transcription factor highly expressed in thyroid follicle cells and type II alveolar epithelial cells. The expression level of TTF-1 is significantly correlated with growth, development, malignant behavior and prognosis of thyroid and lung cancer [16-18]. In addition, recent studies have suggested that TTF-1 is significantly correlated with growth, development and malignant behavior of cervical small cell neuroendocrine carcinomas, ovarian cancer and some rare intracranial tumors [14, 19, 20].

In this study, we examined the expression of DFF45 and TTF-1 in benign and malignant lesions of the gallbladder by immunohistochemistry. To the best of our knowledge, this is the first study of DFF45 and TTF-1 expression in benign and malignant gallbladder lesions. In addition, the expression of DFF45 and TTF-1 was correlated with clinicopathologic characteristics, clinical behavior prognosis of adenocarcinomas, and patient survival.

\section{Material and methods}

\section{Case selection}

A total of 204 specimens (108 adenocarcinomas, 46 corresponding peritumoral tissues, 15 gallbladder polyps and 35 chronic cholecystitis tissues) were included in this study. All diagnoses were based on morphological criteria, immunohistochemical staining, and clinical findings. Surgery included radical resection for 34 adenocarcinomas (31.5\%), palliative surgery for 48 adenocarcinomas (44.4\%), and no operation with only surgical biopsy for 26 cases $(24.1 \%)$. Detailed clini- copathological characteristics of the specimens are presented in Table I. Survival information for 67 patients with adenocarcinoma was obtained through letters and phone calls. Twenty patients (29.9\%) survived over 1 year and $47(70.1 \%)$ patients survived less than 1 year.

All experiments were performed in full agreement with ethics and international conventions. Ethics Committee approval was obtained from the Ethic Committee for Human Study of Central South University.

\section{Immunohistochemistry}

Immunohistochemistry was performed on formalinfixed, paraffin-embedded tissue samples. Rabbit antihuman DFF45/ICAD and TTF-1 antibodies were purchased from Santa Cruz Biotechnology (Santa Cruz, CA, USA). For visualization, a ChemMate TMEnVison $+/ \mathrm{HRP} / \mathrm{DAB}$ staining kit was used according to the manufacturer's protocol. Briefly, the sections were deparaffinized and then incubated with peroxidase inhibitor $\left(3 \% \mathrm{H}_{2} \mathrm{O}_{2}\right)$ in the dark for 10 minutes, followed by a EDTA-trypsin digestion for 15 minutes. The sections were incubated with primary antibody for $60 \mathrm{~min}$ utes at $37^{\circ} \mathrm{C}$. Slides were then rinsed in PBS and incubated for 30 minutes at $37^{\circ} \mathrm{C}$ with solution A from the Dako ChemMate ${ }^{\mathrm{TM}}$ staining kit. 3,3'-Diaminobenzidine (DAB) substrate was added for 15 minutes followed by hematoxylin counter-staining. The slides were then dehydrated with different concentrations (70-100\%) of ethanol, soaked in xylene for 15 minutes and mounted in neutral balsam.

The percentage of positive DFF45 or TTF-1 cells was calculated from 10 random microscopic fields. The sections with $\geq 25 \%$ positive cells were denoted as positive whereas the sections with less than $25 \%$ positive cells were denoted as negative.

\section{Statistical analysis}

Data were analyzed using SPSS 13.0. The correlation between DFF45 and TTF-1 expression with clinicopathological characteristics was analyzed using $\chi^{2}$ independent tests. Fisher's exact probability test was used for analyzing associations between the two independent sample groups. Correlations were considered significant when the two-tailed p-value was less than 0.05. Kaplan-Meier and log-rank tests were used for univariate survival analysis. The Cox proportional hazards model was used for multivariate analyses and to determine the $95 \%$ confidence interval (95\% CI).

\section{Results}

\section{DFF45 and TTF-1 expression in benign and malignant lesions of gallbladder}

Immunohistochemical analysis revealed that DFF45 positive staining was mainly localized in the cytoplasm 
Table I. Specimens used in the study and corresponding patient clinicopathological characteristics

\begin{tabular}{|c|c|}
\hline \multicolumn{2}{|l|}{ SPECIMEN TYPE AND CLINICOPATHOLOGICAL CHARACTERISTICS } \\
\hline Adenocarcinoma (n) & 108 \\
\hline age $($ mean $\pm S D)$, years & $35-70(52.6 \pm 11.2)$ \\
\hline male, $\mathrm{n}(\%)$ & $31(28.7)$ \\
\hline female, n $(\%)$ & $77(71.3)$ \\
\hline invasion into gallbladder surrounding tissues and organs, $\mathrm{n}(\%)$ & $59(54.6)$ \\
\hline regional lymph node metastasis, $\mathrm{n}(\%)$ & $59(54.6)$ \\
\hline presence of gallstones, $\mathrm{n}(\%)$ & $58(53.7)$ \\
\hline histopathologic subtypes, n (\%) & \\
\hline adenoma canceration & $9(8.2)$ \\
\hline well-differentiated adenocarcinoma & $29(26.9 \%)$ \\
\hline moderately differentiated adenocarcinoma & $29(26.9 \%)$ \\
\hline poorly differentiated adenocarcinoma & $30(27.8)$ \\
\hline mucinous adenocarcinoma & $11(10.2)$ \\
\hline Peritumoral tissue (distance from the tumor $\geq 3 \mathrm{~mm}$ ) (n) & 46 \\
\hline normal, n $(\%)$ & $10(21.7)$ \\
\hline mild dysplasia, n $(\%)$ & $10(21.7)$ \\
\hline moderate dysplasia, n (\%) & $12(26.1)$ \\
\hline severe dysplasia, n (\%) & $14(30.5)$ \\
\hline Gallbladder polyps $(\varphi=8-15 \mathrm{~mm})(\mathrm{n})$ & 15 \\
\hline male, $\mathrm{n}(\%)$ & $5(33.3)$ \\
\hline female, n (\%) & $10(66.7)$ \\
\hline normal to mild dysplasia, n (\%) & $10(66.7)$ \\
\hline moderate to severe dysplasia, n (\%) & $5(33.3)$ \\
\hline Chronic cholecystitis ( $\mathrm{n}$ ) & 35 \\
\hline chronic cholecystitis, $\mathrm{n}(\%)$ & $15(42.9)$ \\
\hline chronic cholecystitis accompanied by gallbladder stone, $\mathrm{n}(\%)$ & $20(57.1)$ \\
\hline normal gallbladder mucosa & $11(31.4)$ \\
\hline mild dysplasia & $12(34.3)$ \\
\hline moderate dysplasia & $7(20.0)$ \\
\hline severe dysplasia & $5(14.3)$ \\
\hline
\end{tabular}

and/or the cell nucleus (Fig. 2A and 2B), while TTF-1 positive staining was mainly localized in the nucleus and/or cytoplasm (Fig. 2C and 2D). The expression of DFF45 and TTF-1 was significantly higher in gallbladder adenocarcinoma than in the corresponding adjacent peritumoral tissues, adenomatous polyps and chronic cholecystitis epithelium (all p $<0.05$ ) (Table II).

DFF45 and TTF-1 expression and clinicopathological characteristics of gallbladder adenocarcinomas

As shown in Table III, the positive immunohistochemical reaction for DFF45 and TTF-1 was significantly more frequent in well-differentiated adenocarcinomas with no lymph node metastasis and no invasion, as compared to the poorly differentiated adenocarcinomas with lymph node metastasis and invasion to the gallbladder surrounding tissues and organs (all $\mathrm{p}<0.05)$. DNA fragmentation factor 45 and TTF- 1 exhibited no significant association with mucinous adenocarcinoma or other clinicopathological characteristics, such as sex, age, and history of gallstones $(\mathrm{p}>0.05)$.
The relationship between DFF 45 and TTF-1 expression in gallbladder adenocarcinomas

Of the 45 DFF 45 positive adenocarcinomas, TTF- 1 was positively expressed in 38 cases, while of the 63 DFF45 negative adenocarcinomas, TTF-1 was negatively expressed in 13 cases $\left(\chi^{2}=32.82\right.$, $\left.\mathrm{p}<0.01\right)$, suggesting a high consistency between the expression of DFF45 and TTF-1 in gallbladder adenocarcinomas.

\section{DFF45 and TTF-1 expression and survival of} patients with gallbladder adenocarcinoma

In this study, the survival information was available for 67 of the 108 patients with gallbladder adenocarcinoma. Positive DFF 45 and TTF-1 immunohistochemical expression was present in $27 / 67$ (40.3\%) and $32 / 67(47.8 \%)$ of the analyzed samples, respectively.

The Kaplan-Meier survival analysis revealed that the histological type $(p=0.031)$, tumor size $(p=0.003)$, lymph node metastasis $(\mathrm{p}=0.005)$, invasion $(\mathrm{p}=$ $=0.002)$ and operative procedure $(\mathrm{p}<0.001)$ were significantly associated with the average survival time of patients. The average survival time of patients with DFF 45 and TTF-1 positive specimens was significantly 

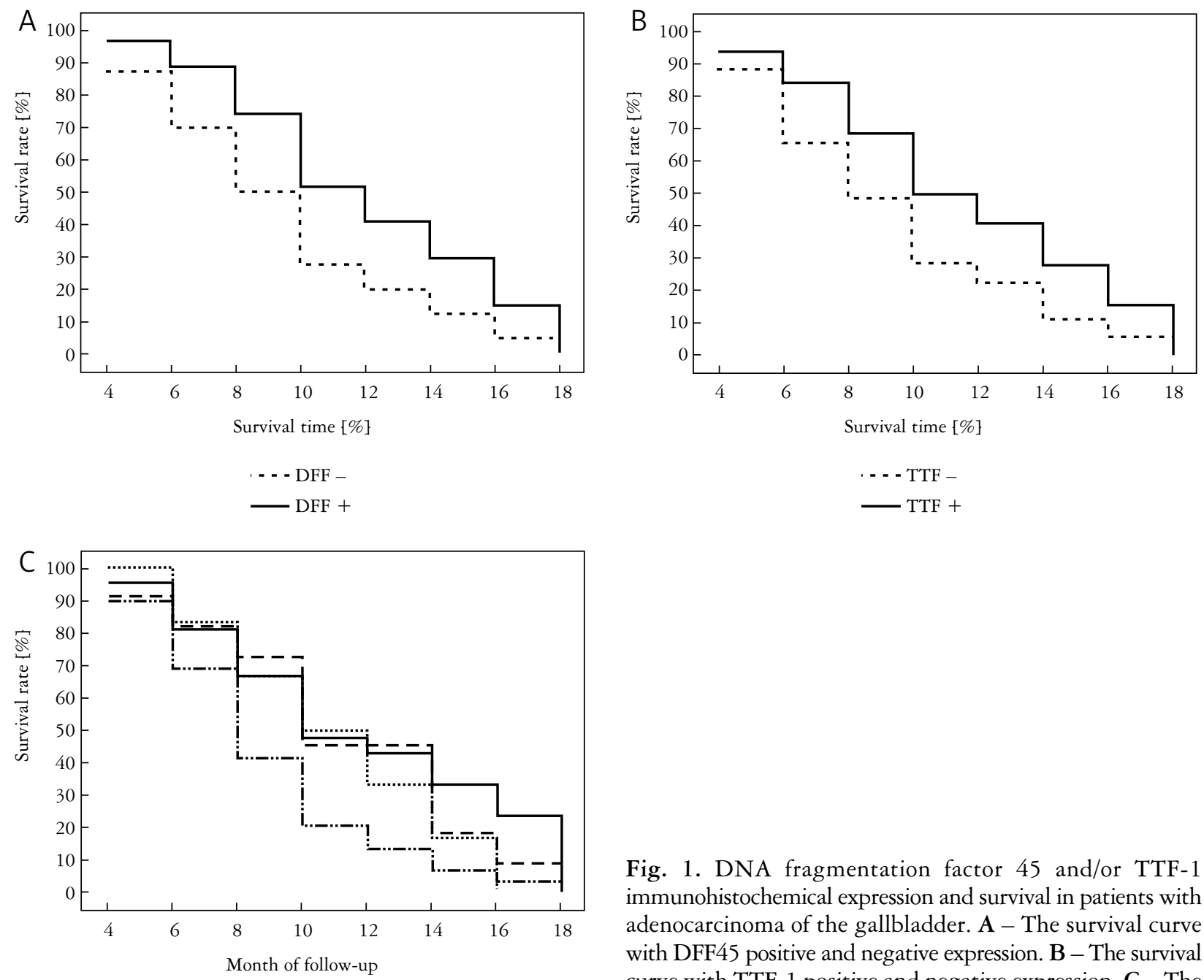

Fig. 1. DNA fragmentation factor 45 and/or TTF-1 immunohistochemical expression and survival in patients with adenocarcinoma of the gallbladder. A - The survival curve with DFF 45 positive and negative expression. B - The survival curve with TTF-1 positive and negative expression. $\mathrm{C}-$ The survival curve in patients with gallbladder adenocarcinoma with DFF45 (+) (-) and TTF-1 (+) (-) expression

higher than those with negative expression $(p=0.025$ and $p=0.042$, respectively) (Table IV, Fig. $1 \mathrm{~A}$ and 1B). Cox multivariate analysis showed that the tumor size $(\geq 2 \mathrm{~cm})$, lymph node metastasis, invasion, as well as DFF45 and TTF-1 negative expression negatively correlated with postoperative survival, yet positively correlated with mortality, suggesting that DFF45 and TTF-1 are relative risk factors on prognosis in GBC (Table V).

\section{Discussion}

The ability of tumor cells to evade apoptosis is one of the key hallmarks of cancer [21]. Several apoptotic pathways have been described, identifying caspase3 and caspase- 7 as key effector molecules in apoptosis $[22,23]$. DNA fragmentation factor 45 is a caspase- 3 or caspase- 7 substrate that must be cleaved before apoptotic DNA fragmentation can proceed.

Table II. The expression of DFF45 and TTF-1 in the benign and malignant lesions of the gallbladder

\begin{tabular}{lccccccc}
\hline Tissue TYPE (NUMBER OF SAMPLES) & \multicolumn{3}{c}{ DFF45 } & \multicolumn{3}{c}{ TTF-1 } \\
\cline { 2 - 7 } & $\begin{array}{l}\text { Positive } \\
\text { N }(\%)\end{array}$ & $\chi^{2}$ & $\mathrm{P}^{*}$ & $\begin{array}{c}\text { Positive } \\
\text { N }(\%)\end{array}$ & $\chi^{2}$ & $\mathrm{P}^{*}$ \\
\hline gallbladder adenocarcinoma (108) & $45(41.7)$ & & & $56(51.7)$ & & \\
\hline peritumoral tissue (46) & $9(19.6)$ & 6.92 & $<0.01$ & $12(26.1)$ & 8.68 & $<0.01$ \\
\hline polyp (15) & $2(13.3)$ & 4.49 & $<0.05$ & $3(20.0)$ & 5.35 & $<0.05$ \\
\hline chronic cholecystitis (35) & $3(8.6)$ & 12.98 & $<0.01$ & $4(11.4)$ & 17.74 & $<0.01$ \\
\hline
\end{tabular}

*DFF 45 and TTF-1 expression in a specific tissue compared to the expression in gallbladder adenocarcinoma 

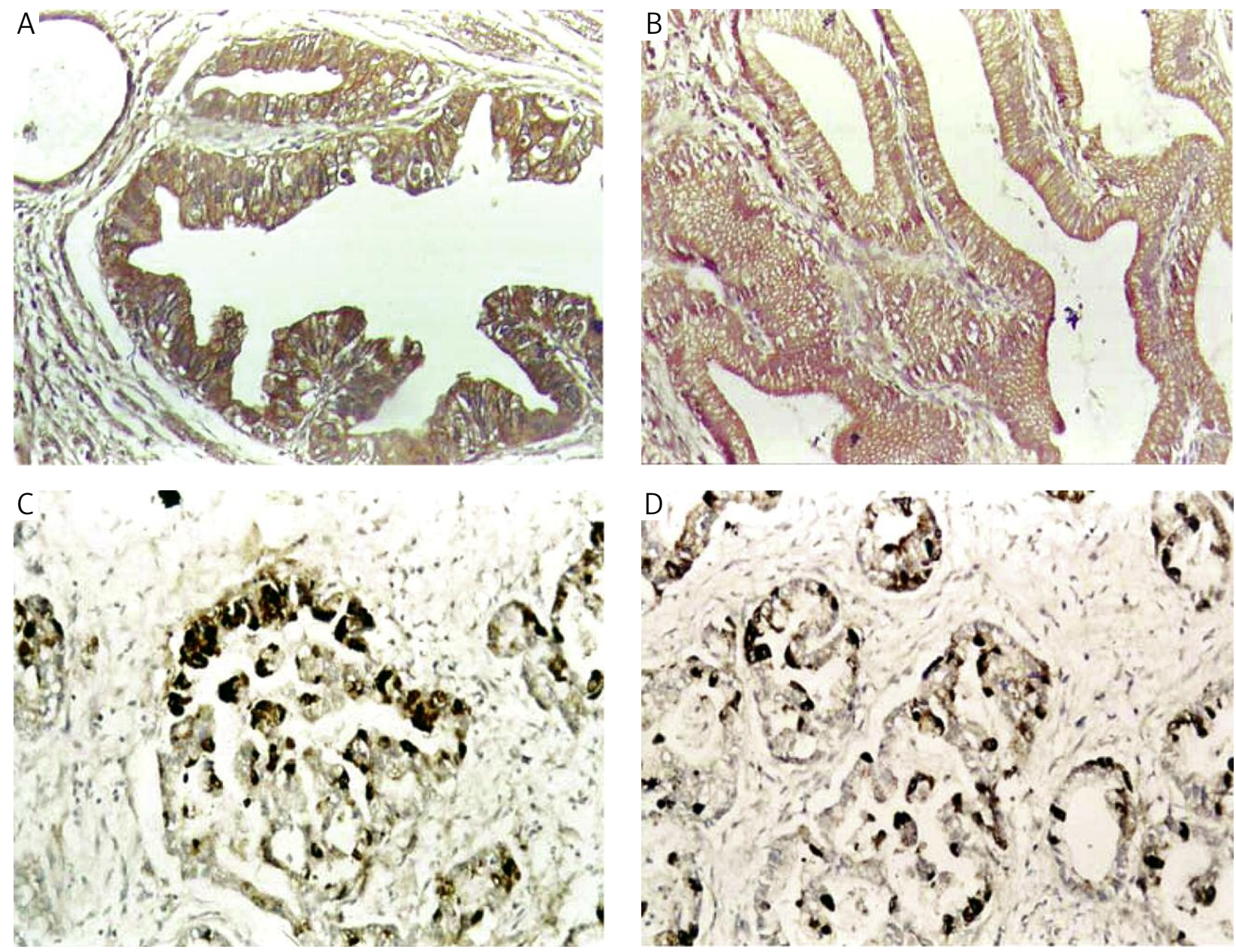

Fig. 2. DNA fragmentation factor 45 and TTF-1 expression in the benign and malignant lesions of the gallbladder. DFF45 positive immunohistochemical reaction was mainly localized in the cytoplasm and TTF-1 positive immunohistochemical reaction was mostly localized in the nucleus. A - DFF45 positive expression in a well-differentiated adenocarcinoma. B - DFF45 positive expression in an atypical hyperplasia of gallbladder epithelium in chronic cholecystitis. C - TTF-1 positive expression in a moderately differentiated adenocarcinoma. D - TTF-1 positive expression in a moderately atypical hyperplasia of gallbladder epithelium in polyp (original magnification $200 \times$ )

DNA fragmentation factor 45 forms a heterodimer with DFF40, a $40 \mathrm{kDa}$ endonuclease, and acts both as its specific inhibitor and as a chaperone in its appropriate folding $[7,8]$. When caspase- 3 is activated by apoptotic stimuli, it cleaves DFF45 at two sites, which causes the release and activation of DFF40, leading to the generation of double-stranded breaks in internucleosomal chromatin regions and chromatin condensation [11].

Thus, aberrant DFF45 expression might influence tumor development and progression and DFF45 may play a role in malignant transformation and metastasis. Indeed, DFF45 expression was down-regulated or lost in neuroblastoma, endometrial carcinoma, ovarian carcinoma, esophageal carcinoma, gastroenteric carcinoma, bladder carcinoma and germinoma. In addition, in some tumor types, DFF45 expression correlated with tumor progression, differentiation, metastasis and prognosis. Taken together, these findings support a tumor suppressor role of DFF45 [8, 10, 12, 13, 15, 24].
Tissue-specific transcription factors are important regulators of cell determination and differentiation. Thyroid transcription factor 1, also known as NKX-2.1, is a tissue-specific transcription factor expressed in the thyroid and lung [25]. Thyroid transcription factor 1 binds to the thyroglobulin and thyroid peroxidase gene promoters and regulates the expression of thyroidspecific genes, and thus has an important role in thyroid growth and development. In addition, TTF-1 is highly expressed in type II alveolar epithelial cells and is essential for lung morphogenesis and differentiation. Recent findings show that TTF-1 expression level is significantly correlated with growth, development, malignant behavior and prognosis of thyroid carcinoma and non-small-cell lung cancer (NSCLC). Tumors with high TTF-1 expression are well differentiated, progress slowly with almost no lymph node metastasis, and usually have a good prognosis $[16,18,24]$. In addition, many studies show that TTF- 1 expression is significantly correlated with growth, development, malignant be- 
Table III. The association of DFF45 and TTF-1 expression with the clinicopathological characteristics of gallbladder adenocarcinoma

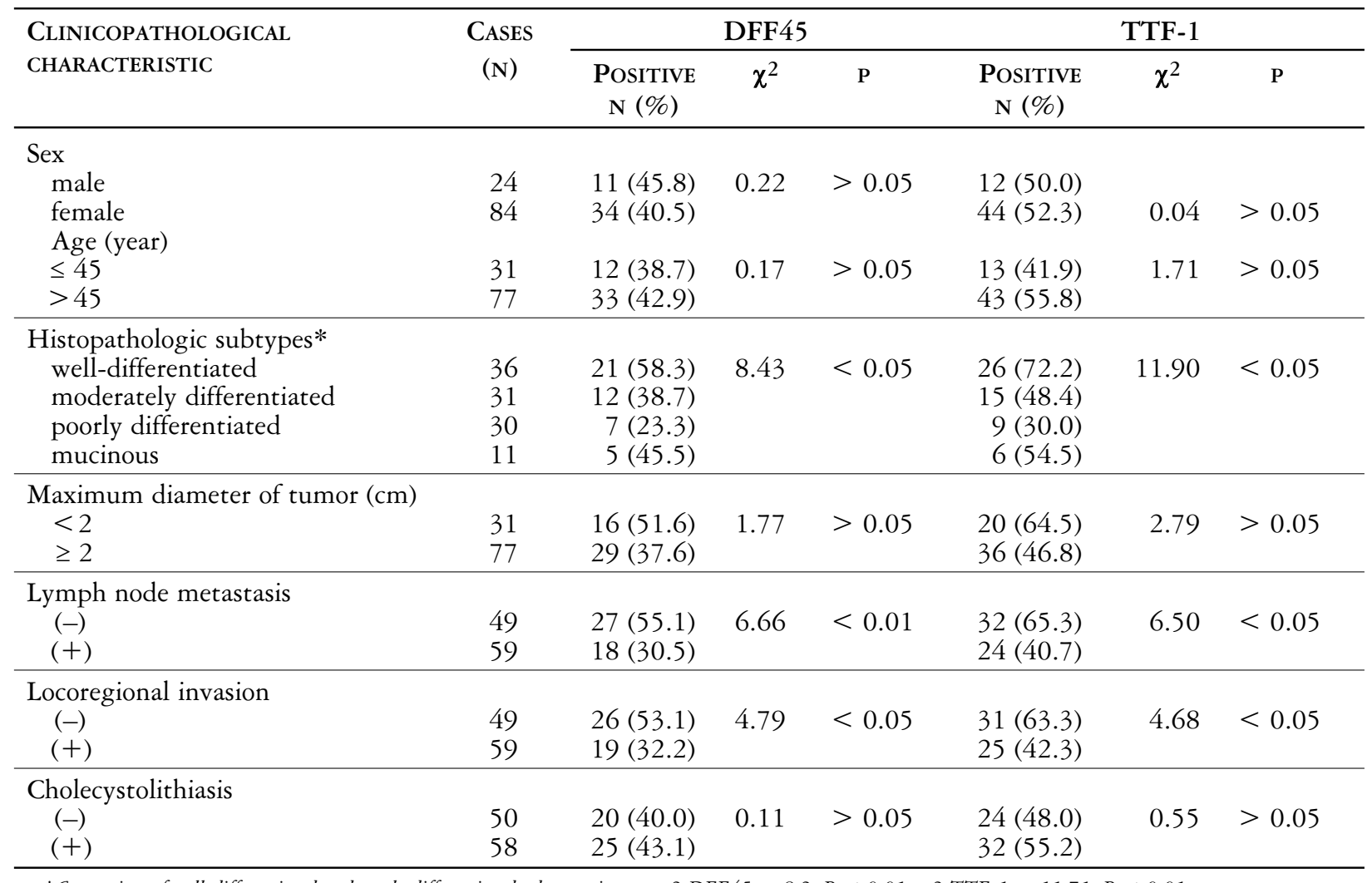

*Comparison of well-differentiated and poorly differentiated adenocarcinoma: 2 DFF45 $=8.2, P<0.01 ; \quad 2$ TTF-1 $=11.71, P<0.01$

havior and prognosis of other tumors, such as cervical small cell neuroendocrine carcinomas, ovarian cancer and some rare intracranial tumors $\{14,19,20]$.

In our study we examined the expression of DFF45 and TTF- 1 in benign and malignant gallbladder lesions by immunohistochemistry. We found that DFF45 and TTF-1 expression was significantly higher in well-differentiated adenocarcinomas without lymph node metastasis and locoregional invasion compared to poorly differentiated adenocarcinomas with lymph node metastasis. Moreover, patients with tumors with higher DFF 45 and TTF-1 expression had better prognosis. Since the cleavage of DFF 45 by caspase- 3 is an important step in the apoptotic pathway, down-regulation or loss of DFF45 expression in neoplastic tissues might result in the blockage of the caspase- 3 mediated apoptotic pathway and consequently lead to tumor progression. Thus, our findings are in agreement with the tumor suppressor role of DFF $45[4,11,26]$.

In addition, DFF 45 and TTF- 1 protein expression in gallbladder adenocarcinomas was significantly higher than that in the corresponding peritumoral tissues, adenomatous polyps or chronic cholecystitis epithelium. Furthermore, DFF 45 and/or TTF-1 expression was significantly higher in well-differentiated adenocarcinomas $<2 \mathrm{~cm}$ in diameter without lymph node metastasis and locoregional invasion. The survival time was longer in patients with tumors positive for DFF45 and TTF- 1 than those with negative expression, as shown by the Kaplan-Meier survival analysis.

Another interesting finding of this study was that DFF 45 and TTF-1 expression levels significantly correlated with each other in gallbladder adenocarcinomas, which may be related to their respective biological functions.

The results of the Cox multivariate analysis suggest that positive expression of DFF 45 and TTF-1 positively correlated with the postoperative survival rate and negatively correlated with the death rate. In addition, DFF45 and TTF- 1 were found to be independent prognostic factors for gallbladder adenocarcinomas.

Finally, the results of our study suggest that the expression levels of DFF 45 and/or TTF-1 are closely related to the carcinogenesis, clinical behavior, and prognosis of gallbladder adenocarcinoma. Based on our results we can conclude that the expression of DFF 45 and TTF- 1 could be used as new potential biomarkers and/or targets for GBC therapy.

The authors declare no conflict of interest. 
Table IV. Relationship between DFF45 and TTF-1 expression, clinicopathological characteristics and average survival of gallbladder adenocarcinoma patients

\begin{tabular}{|c|c|c|c|}
\hline $\begin{array}{l}\text { CLINICOPATHOLOGICAL } \\
\text { CHARACTERISTICS }\end{array}$ & $\begin{array}{l}\text { SAMPLES } \\
(\mathrm{N})\end{array}$ & $\begin{array}{c}\text { AVERAGE } \\
\text { SURVIVAL (MONTHS) }\end{array}$ & $\mathbf{P}$ \\
\hline $\begin{array}{l}\text { Sex } \\
\text { male } \\
\text { female }\end{array}$ & $\begin{array}{l}19 \\
48\end{array}$ & $\begin{array}{l}10.0(4-16) \\
10.0(4-18)\end{array}$ & 0.910 \\
\hline $\begin{array}{l}\text { Age } \\
\leq 45 \\
>45\end{array}$ & $\begin{array}{l}11 \\
56\end{array}$ & $\begin{array}{l}8.0(4-14) \\
10.0(4-18)\end{array}$ & 0.121 \\
\hline $\begin{array}{l}\text { Histopathologic subtypes } \\
\text { adenoma canceration } \\
\text { well-differentiated } \\
\text { moderately differentiated } \\
\text { poorly differentiated } \\
\text { mucinous }\end{array}$ & $\begin{array}{r}8 \\
20 \\
20 \\
12 \\
7\end{array}$ & $\begin{array}{l}12.0(8-18) \\
10.0(4-18) \\
10.0(4-18) \\
8.0(4-10) \\
10.0(6-16)\end{array}$ & 0.031 \\
\hline $\begin{array}{l}\text { Maximum diameter of tumor }(\mathrm{cm}) \\
\quad<2 \mathrm{~cm} \\
\geq 2 \mathrm{~cm}\end{array}$ & $\begin{array}{l}20 \\
47\end{array}$ & $\begin{array}{l}14.0(4-18) \\
8.0(4-18)\end{array}$ & 0.003 \\
\hline $\begin{array}{l}\text { Lymph node metastasis } \\
(-) \\
(+)\end{array}$ & $\begin{array}{l}36 \\
31\end{array}$ & $\begin{array}{c}12.0(4-18) \\
8.0(4-18)\end{array}$ & 0.005 \\
\hline $\begin{array}{l}\text { Locoregional invasion } \\
(-) \\
(+)\end{array}$ & $\begin{array}{l}39 \\
28\end{array}$ & $\begin{array}{l}10.0(4-18) \\
8.0(4-16)\end{array}$ & 0.002 \\
\hline $\begin{array}{l}\text { DFF45 expression } \\
\quad+ \\
-\end{array}$ & $\begin{array}{l}27 \\
40\end{array}$ & $\begin{array}{l}11.9(4-18) \\
9.4(4-18)\end{array}$ & 0.025 \\
\hline $\begin{array}{l}\text { TTF-1 expression } \\
\quad+ \\
-\end{array}$ & $\begin{array}{l}32 \\
35\end{array}$ & $\begin{array}{l}11.6(4-18) \\
9.4(4-18)\end{array}$ & 0.042 \\
\hline $\begin{array}{l}\text { DFF45 and TTF-1 expression } \\
\text { DFF45(+)TTF-1(+) } \\
\text { DFF45(+)TTF-1(-) } \\
\text { DFF45(-)TTF-1(+) } \\
\text { DFF45(-)TTF-1(-) }\end{array}$ & $\begin{array}{r}21 \\
6 \\
11 \\
29\end{array}$ & $\begin{array}{l}11.8(4-18) \\
1.0(4-16) \\
11.3(4-18) \\
8.9(4-18)\end{array}$ & 0.049 \\
\hline
\end{tabular}

Table V. Multivariate Cox regression analysis of survival rate in 67 gallbladder adenocarcinoma patients

\begin{tabular}{|c|c|c|c|c|c|c|}
\hline \multirow[t]{2}{*}{ GROUP FACTOR } & \multirow{2}{*}{$\begin{array}{l}\text { REGRESSION } \\
\text { COEFFICIENT }\end{array}$} & \multirow{2}{*}{$\begin{array}{l}\text { STANDARD } \\
\text { ERROR }\end{array}$} & \multirow{2}{*}{$\begin{array}{l}\text { RELATIVE } \\
\text { RISK }\end{array}$} & \multirow[t]{2}{*}{$\mathbf{P}$} & \multicolumn{2}{|c|}{$95 \% \mathrm{CI}$} \\
\hline & & & & & LOWER LIMIT & UPPER LIMIT \\
\hline $\begin{array}{l}\text { Pathology type adenoma, } \\
\text { well-/moderately/poorly } \\
\text { differentiated, mucinous } \\
\text { adenocarcinoma }\end{array}$ & 0.558 & 0.293 & 1.75 & 0.089 & 0.98 & 3.10 \\
\hline $\begin{array}{l}\text { tumor diameter } \\
<2.0 / \geq 2.0 \mathrm{~cm}\end{array}$ & 0.899 & 0.336 & 2.46 & 0.039 & 1.27 & 4.75 \\
\hline metastasis of lymph node $\mathrm{n} / \mathrm{y}$ & 1.087 & 0.399 & 2.97 & 0.020 & 1.36 & 6.48 \\
\hline $\begin{array}{l}\text { invasiveness of regional } \\
\text { tissues } n / y\end{array}$ & 1.236 & 0.421 & 3.44 & 0.017 & 1.51 & 7.86 \\
\hline 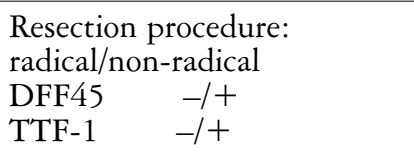 & $\begin{array}{r}1.403 \\
-0.703 \\
-0.611\end{array}$ & $\begin{array}{l}0.513 \\
0.321 \\
0.290\end{array}$ & $\begin{array}{l}4.07 \\
0.50 \\
0.54\end{array}$ & $\begin{array}{l}0.005 \\
0.031 \\
0.047\end{array}$ & $\begin{array}{l}1.49 \\
0.26 \\
0.31\end{array}$ & $\begin{array}{r}11.12 \\
0.93 \\
0.96\end{array}$ \\
\hline
\end{tabular}




\section{References}

1. Jayaraman S, Jarnagin WR. Management of gallbladder cancer. Gastroenterol Clin North Am 2010; 39: 331-342.

2. Jemal A, Siegel R, Ward E, et al. Cancer statistics, 2008. CA Cancer J Clin 2008; 58: 71-96.

3. Wistuba II, Albores-Saavedra J. Genetic abnormalities involved in the pathogenesis of gallbladder carcinoma. J Hepatobiliary Pancreat Surg 1999; 6: 237-244.

4. Hsing AW, Gao YT, Han TQ, et al. Gallstones and the risk of biliary tract cancer: a population-based study in China. Br J Cancer 2007; 97: 1577-1582.

5. Hawkins WG, DeMatteo RP, Jarnagin WR, et al. Jaundice predicts advanced disease and early mortality in patients with gallbladder cancer. Ann Surg Oncol 2004; 11: 310-315.

6. Wistuba II, Gazdar AF. Gallbladder cancer: lessons from a rare tumour. Nat Rev Cancer 2004; 4: 695-706.

7. Ding H, Qiu S, Li S, et al. Expression, purification, crystallization of fragments from the C-terminal region of DFF45/ICAD. Acta Crystallogr D Biol Crystallogr 2003; 59: 1323-1326.

8. Zhang J, Guo H, Qian G, et al. MiR-145, a new regulator of the DNA fragmentation factor-45 (DFF45)-mediated apoptotic network. Mol Cancer 2010; 9: 211.

9. Abel F, Sjöberg RM, Ejeskär K, et al. Analyses of apoptotic regulators CASP9 and DFFA at 1P36.2, reveal rare allele variants in human neuroblastoma tumours. Br J Cancer 2002; 86: 596-604.

10. Konishi S, Ishiguro H, Shibata $\mathrm{Y}$, et al. Decreased expression of DFF45/ICAD is correlated with a poor prognosis in patients with esophageal carcinoma. Cancer 2002; 95: 2473-2478.

11. Banas T, Skotniczny K, Basta A. DFF45 expression in ovarian endometriomas. Eur J Obstet Gynecol Reprod Biol 2009; 146 : 87-91.

12. Takahashi M, Ozaki T, Takahashi A, et al. DFF45/ICAD restores cisplatin-induced nuclear fragmentation but not DNA cleavage in DFF45-deficient neuroblastoma cells. Oncogene 2007; 26: 5669-5673.

13. Hirose M, Sun A, Okubo T, et al. Detection of non-papillary, non-invasive transitional cell G1 carcinoma as revealed by increased DNA instability and other cancer markers. Eur J Histochem 2005; 49: 199-209.

14. Zhang PJ, Gao HG, Pasha TL, et al. TTF-1 expression in ovarian and uterine epithelial neoplasia and its potential significance, an immunohistochemical assessment with multiple monoclonal antibodies and different secondary detection systems. Int J Gynecol Pathol 2009; 28: 10-18.

15. Brustmann H. Poly(ADP-ribose) polymerase (PARP) and DNAfragmentation factor (DFF45): expression and correlation in normal, hyperplastic and neoplastic endometrial tissues. Pathol Res Pract 2007; 203: 65-72.

16. Anagnostou VK, Syrigos KN, Bepler G, et al. Thyroid transcription factor 1 is an independent prognostic factor for patients with stage I lung adenocarcinoma. J Clin Oncol 2009; 27: 271-278.

17. Haque AK, Syed S, Lele SM, et al. Immunohistochemical study of thyroid transcription factor-1 and HER2/neu in non-small cell lung cancer: strong thyroid transcription factor-1 expression predicts better survival. Appl Immunohistochem Mol Morphol 2002; 10: 103-109.

18. Lanzafame S, Caltabiano R, Puzzo L, Cappellani A. Thyroid transcription factor 1 (TTF-1) and $\mathrm{p} 63$ expression in two primary thyroid papillary carcinomas of branchial cleft cysts. Virchows Arch 2006; 449: 129-133.

19. Lee EB, Tihan T, Scheithauer BW, et al. Thyroid transcription factor 1 expression in sellar tumors: a histogenetic marker? J Neuropathol Exp Neurol 2009; 68: 482-488.

20. McCluggage WG, Kennedy K, Busam KJ. An immunohistochemical study of cervical neuroendocrine carcinomas: Neoplasms that are commonly TTF1 positive and which may express CK20 and P63. Am J Surg Pathol 2010; 34: 525-532.
21. Hanahan D, Weinberg RA. The hallmarks of cancer. Cell 2000; 100: 57-70.

22. Chen CY, Chang CY, Liu HJ, et al. Apoptosis induction in BEFV-infected Vero and MDBK cells through Src-dependent JNK activation regulates caspase- 3 and mitochondria pathways. Vet Res 2010; 41: 15.

23. Hobbs JA, Hommel-Berrey G, Brahmi Z. Requirement of caspase- 3 for efficient apoptosis induction and caspase- 7 activation but not viral replication or cell rounding in cells infected with vesicular stomatitis virus. Hum Immunol 2003; 64: 82-92.

24. Bongiovanni M, Sadow PM, Faquin WC. Poorly differentiated thyroid carcinoma: a cytologic-histologic review. Adv Anat Pathol 2009; 16: 283-289.

25. Fabbro D, Di Loreto C, Stamerra O, et al. TTF-1 gene expression in human lung tumours. Eur J Cancer 1996; 32A: 512-517.

26. Abel F, Sjöberg RM, Krona C, et al. Mutations in the N-terminal domain of DFF45 in a primary germ cell tumor and in neuroblastoma tumors. Int J Oncol 2004; 25: 1297-1302.

\section{Address for correspondence}

\section{Zhu-Lin Yang}

Research Laboratory of Hepatobiliary Diseases

The Second Xiangya Hospital of Central South University

Renmin Road, Changsha 410011, China

tel. $+86-13974830358$

fax +86-731-88618423

e-mail: yangzhulin8@sina.com 